stances, it might be explained by propagation of the pulmonary murmur downwards.

The results of a minuter examination of the different parts were as follows:-A section of the white medullary-looking mass at the entrance of the vessels into the lung showed a soft, translucent snbstance, through which were scattered opaque, white spots of greater density. Both exhibited a cancerous juice, and, subjected to the microscope, were found to consist of a fibroid matrix, full of nuclei and small cells. The difference between the two substances consisted in this, that the opaque matter contained large quantities of dark glomeruli, as if in them an active process were being carried on. A portion of the denser white substance, taken from the base of the lung, showed a similar struoture; but there was more fibroid tissue, and there were compound cells, together with many glomeruli. The thickened pleura contained new growth, evidently malignant, consisting of nuclei, oval cells, and fusiform cells. The circular yellow, softened deposits subjacent to the pleura, and before stated to present to the naked eye the appearance of tubercle, were not to be distinguished from this substance by the microscope; they consisted of a fine granular matter, particles of free oil, granular nuclear corpuscles, (with a faint outline, and quite distinct from the nuclei seen in the other morbid growths, ) and glomeruli.

I have no hesitation in pronouncing it to have been a case in which cancer and tubercle were associated; and although the gangrenous condition of the entire lung left me in the dark as to the state of the organ previous to the occurrence of the gangrene, the whole history of the case, the duration of the cough, the gradual emaciation, and the hæmoptysis seven or eight months before coming under observation, indicate tuberculosis as the commencement of the series, the malignant growth being superadded at an advanced period, and by its pressure inducing an arrest in the nutrition of the lung. The whole apex and the greater part of the lung, except the base and root, did not exhibit the appearance of cancerous growth. The induration might have resulted from pneumonia; but, taking into consideration the cavities in the lung, the peculiar hard appearance of the deposit, and moreover the naked-eye and microscopic appearance of the yellow nodules, which retained their peculiar colour and were not involved in the prevailing gangrenous hue, the probabilities seem to me, by negative and positive evidence, to favour the view that tuberele was the primary, cancer the secondary affection. It must, however, be admitted that it might be urged that there was no tubercle in the right lung. That this raises a difficulty is true; but as we do sometimes find tubercle limited to one lung, and there seems to be no other satisfactory mode of explaining the varions phenomena by having recourse to other processes of reasoning, I still think the balance of evidence in favour of the previous argument.

Although the case just related is in its particulars an unusual one, it serves to illustrate the mode in which, no doubt often, persistent pulmonary murmurs are produced, - namely, by pressure from morbid bronchial glands behind, and by pressure of a superincumbent portion of indurated and hypertrophied lung from before. If these circumstances are conjoined, we are likely to find the murmur at all times and in all postures of the body; where only one exists at a time, change of posture, as in the young gentleman alluded to. will probably cause the murmur to cease, or materially modify it-a result not brought about in aortic or mitral disease. The character of the murmur does not suffice to establish the diagnosis. Within the last fortnight a young woman of tolerably healthy aspect, who came to me with cardiac symptoms, exhibited so loud and well-marked a pulmonary bruit, that it seemed necessarily to result from a change in the calibre of the channel through which the blood passed; the entire absence of dulness on percussion forbad the idea of there being any tubercular deposit, yet I was not prepared for the complete disappearance of the murmur when $I$ examined her a few days after the first consultation. Here the explanation may, perhaps, lie in an anæmic condition of the blood.

It has not been my object in this communication to exhaust the topic of pulmonary murmurs, therefore I do not now inquire into other extraneous influences which, doubtless, may inciuce them; as, for instance, pericardial effusion, aortic dila. tation, morbid growths in the anterior mediastinum, and the like. I would merely add one word as to the necessity of distinguishing a murmur produced, by whatever cause, in the pulmonary artery, from one originating in the subclavian of of the left side. We often find, especially in tubercular disease, and perhaps chiefly in the early stages of phthisis pulmoaalis, a subclavian murmur produced by pressure of the indu. rated lung, or in inspiration by compression of the artery as it passes behind the subclavian muscle and crosses the first rib; this murmur, again, which is of a short, blowing character, is distinct from the propagated heart sounds, which are also, under similar circumstances, heard in the clavicular region; and are, perhaps, more valuable in a diagnostic $p$,int of view than the subclavian murmur. The murmur which is produced in the subclavian artery is heard immediately unde: the clavicle, and is generally not of an intense or prolonged character, as compared with pulmonary murmur, which, again, is limited, as before said, to the site of the pulinonary valves, an $?$ is generally more circumscribed than aortic or mitral mur. murs are.

In conclusion, I would observe that the main practical interest of murmurs produced in the pulmonary artery is dependent upon their connexion with the early stage of phthisis, and in this respect I would especially press the matter upon your notice.

Manchester-sqrare, Feb. 1860.

\section{ANEURISM OF THE ARCH OF THE AORTA.}

By H. G. EARNSHAW, Esq., M.R.C.S.,

SENIOR HOUSE-SURGEON TO THE LIVERPOOL NORTHERN HOSPITAL.

ALtHovgh the following case of thoracic aneurism may possess no therapeutic value, it may perhaps possess interest for some of the readers of THE LA NCET as a pathological study, and to some it may offer points of medical jurisprudence worth consideration. It will also serve, though subordinately, to illustrate those frequent cases of barbarous cruelty practised at sea by officers of the merchant service on their sick and timid seamen; and may, in this way, be of use now that international law on the subject has become a Government question. The admission of the case into the hospital took place some months ago, but as I report it from my note-book, I make use of the tenses in which it there stands :-

Antone $\mathrm{P}-$, aged thirty-four, a coloured man and a seaman, was born at St. Vincent, Cape de Verde Islands. He is a Portuguese, but able to speak English plainly. About six months ago, he was shipped in London with several more men of colour, and signed articles to join the Caledonia, a foreign ship of 1000 tons, then at Havre, in France, and proceed with that vessel to Cuba. The vessel did not, however, sail for Cuba, but to Mobile, in the Southern States of America. At the time of Antone's joining the ship, he was, as he alleges, hale and hearty. A short time before, he had caught cold from lying out in the night air in a fit of drunkenness. A severe congh immediately ensued, which was attended with some expectoration of blood. For the relief of this, he went into one of the London hospitals, where he was under treatment for a week, and was then discharged cured, without having had any intimation conveyed to him that he was the subject of aneurism. This, it may be supposed, from the frequent use that must have been made of the stethoscope, would have happened, if the aneurism had at this time attained much dimension. He next joined his vessel at Havre, and remained there with her four days, at the end of which she sailed in ballast. The voyage to Mobile occupied about two months. Three weeks after leaving Havre, the weather became suddenly severe, and the man took a fresh cold. He lay by, in consequence, for a short time, and was physicked by the captain. He recovered his usual strength and activity; worked the remainder of the passage out without any failing of either; and during the time the vessel was lading with cotton at Mobile, he assisted in the labour like any other of the crew. He states positively that he had no feeling of ailment, and made no complaint from that time until about three weeks ago, when he first found a difficulty in moving about, and was attacked with, as he thought, rheumatic pains in the lower limbs. The difficulty consisted not so much in any vant of voluntary power over these limbs, as of uncertain sensation of the ground he was walking on; and this caused him to lift the feet hastily like a spavined animal, and to put them down with a feeling of insecurity, except when engaged in watching his own movements. In this way he used to stumble and trip on deck, so as to have it thought sometimes by his messmates that he was in liquor. This condition increased on him, and 
attracted his captain's notice, who thought, as he did, that it was nothing but rheumatism, and gave him a stimulating em. brocation to rub on the legs, \&c. He, in a day or two, felt thoroughly sick and unfit for work, but was reluctant to state as much, and he therefore progressed with his duties as well as he was able. Being one day engaged in this manner, one of the under officers strove to hurry him in his movements, and ordered him to make more haste in what he was doing. Antone replied that he was unable to move quicker. The officer retorted "You are soldiering," and raising his foot whilst he was standing a few feet more elevated than Antone, kicked him violently in the back. The man fell at once, but was presently lifted by the officer, and saluted a second time with a slap in the face. From that time Antone was unable to raise himself upright. He was carried below, and there remained until brought to the hospital on a stretcher, when the vessel arrived in this port, as near as possible six months from the time he shipped.

When I proceeded to inquire into his symptoms and condition, his complaint was of a swelling in his back, which he declared had certainly not existed before the officer's kick, and which he believed had been produced by that blow. I examined the back, and found a large, pulsating, circumscribed gwelling, which was the one he referred to, situated at the lower angle of the left scapula. The circumference of its base was about equal to the rim of glass tumbler, and its arc to that of the half of a good-sized orange. It was slightly movable, incompressible, heaved synchronously with the pulse, and was without bruit. He complained also of having lost sensation from below the navel. Over the legs he had a little command of movement--over one a little more than the other, but it was only to the extent of lifting the feet a short way from the bed, and of moving the legs to and fro as he lay upon it. He complained that every now and then, without willing it, they became convulsed. The touch of my hand, either on the limbs or the abdomen, frequently produced these uncontrollable startings. A pin buried anywhere in the flesh as high as the sixth and seventh ribs, though not known to himself, caused these startings also; and when one or the other foot was gently titillated, the opposite one was sometimes inimediately jerked upwards, and there shook convulsively for several seconds. The bladder evacuated its contents naturally, and at will. The bowels had failed to act for a week or more. He was fleshy, and bis appearance bespoke tolerable health and a good habit of body. He betrayed no excessive anxiety of countenance. His appetite was moderate; his pulse weak, especially that at the left wrist.

Sunday was the day of his admission. Monday and Tuesday passed without any change of his condition, except that the pain (about which also he had at first complained) at the site of the tumour increased, and spread around the side to the heart, and over the shoulder to the left breast. To subdue this, he had a drachm of Battley's sedative solution, which soon gave him ease and refreshing sleep. On the Wednesday evening he was conversing with adjoining patients; and having just drunk a cup of tea, supporting himself meanwhile in a half-sitting posture by his outstretched hands, he suddenly drooped on his pillow, and died within two minutes. I exa. mined his back presently, and found that the tumour had almost disappeared, and that the part was at its proper level. Autopsy. - About twenty hours after death I made an examination of the body; and made it, assisted by my colleague, Mr. Weaver, with as much pains as could be taken, partly on account of its being a criminal case and under police investigation. The interspaces within the left side of the chest were occupied with cuagulated hlood. I removed the spine from the first to the eleventh dosal vertebræ, with a few inches of the corresponding ribs on either side, and the contained viscera. I then carefully cut away all but the aorta, from its origin to its thoracic termination, and dissected out a large aneurism. I found it to consist of a reniform tumour, of about the fulness of a dilated adult heart; and I found it lying principally on the left of the spinal column, its fundus being embraced by the clavicle, and its lower end reaching to the root of the tenth rib. Its neck, or hilus, was the part at which it protruded from the aorta, and it commenced an inch below the (left) subclavian, and extended about three inches down. wards. The upper part of the tumour overlapped the bodies of the fourth, fifth, sixth, seventh, and eighth dorsal vertebre, (though but to a small extent of the fourth and eighth), and was, adherent to them, and to the roots of the fourth, fifth, sixth, and seventh ribs of the right side. On the left side, the tumour reposed on, and was adherent to, the inner surfaces of the ribs, from the second to the tentl, and having at about its 138 middle passed backwards to the outside of the chest, it had attached itself to the left side of the spines and laminæe of the seventh, sixth, and fifth dorsal vertebræ. The three left ribs belonging to these vertebræ were broken and comminuted; and thus the aneurism had escaped from the chest at this part. The bodies of the vertebræ-namely, the fourth to the eighth, but especially of the fifth, sixth, and seventh, were much consumed, their respective intervertebral cartilages being unin. jured. 'The fragments of the comminuted ribs were carious, as were also the broken extremities, between which the anenrism had found its way backwards, and so had been able to establish adhesion to the spines and laminæ of the vertebræ, in the manner just explained. Especial notice is deserved of the fact, that of those laminæ the aneurism pressed chiefly on the sixth and fifth, and that these were carious and broken down in fragments; and, through their destruction, contact was effected with the spinal cord itself. The membranes of the cord at this part were very vascular, and the cord itself was soft and pulpy.

It may be borne in mind that, in the history of the case, the man had retained to the last some amount of voluntary motion of the lower extremities, and that from the first the function of sense in these parts had become impaired, and at length totally lost.

In examining the tumour apart from the general anatomy of the disease, there were four points which drew attention espe* cially:-

The first was the fundus of the aneurism. It appeared, on the most careful dissection, to comprise all three coats of the artery, and contained a numerous series of concentric layers of dense white fibrin; and notwithstanding the former inference of the man having been in hospital, of having been frequently stethoscopized in the course of treatment for the pneumonic affection, and of no discovery having been made of the exist. ence of the aneurism, yet its size and solidity, and concentric lamins, will probably lead to the conclusion that its origin was of old date. It occupied that space of the left pleural cavity belonging to the upper lobe of that lung, which pre viously it had pushed forwards and consolidated by its pressure against the front walls of the chest, and then had firmly fastened itself to a small portion of its posterior surface.

The second point was that portion of the aneurism on the bodies of the vertebræ and the roots of the four right ribs. This portion seemed to possess the same characters as the first. The third point was that portion of the aneurism which depended below the neck, extending from the fundus downwards, and adherent to the imner surfaces of the several ribs on the left side, before mentioned, and which extended backwards through the gap in the seventh, sixth, and fifth ribs to the left plates or laminæ, and to the spines of the seventh, sixth, and fifth vertebræ. This portion of the aneurism communicated. with the arta by the same throat as the former two portions; but the two and the one were essentially and plainly unlike in appearance and structure. The two, considering them as one portion, looked, to use the expression, a solid mass, and its parietes were thick, strong, and separable into layers; but the latter, the third portion, being more in a line with the current of the blood, hung downwards three or four inches like a pouch, its walls being flexible and soft, and, from its thinness and structure, inseparable into layers. It contained only a soft coagulum of blood. Its outer surface was dark, and covered with patches of lymph, like a gangrenous intestine. It adhered inwardly and posteriorly to the bodies, laminx, and spines of the seventh, sixth, and fifth vertebræ, and so rotten and insecure seemed its margins of attachment, that I entertained no doubt that here the aneurism had ultimately burst, although, in consequence of the confused state of the structures, no distinct place of rupture could be made out.

The fourth point that attracted notice was a mass of coagn. lated blood lying immediately behind the portion just de. scribed, and infiltrated into the substance of the trapezius muscle. It was enclosed within no sac, and no channel conld be traced between it and the cavity of the aneurism. It was this which had formed the swelling beneath the lower angle of the left shoulder-blade, of which Antone complained when first admitted, and which he stated had been caused by the officer's kick. Within the substance of this coagulum were contained the comminuted fragments of the seventh, sixth, and fifth ribs.

The weight of blood within the left pleural sac was five pounds eight ounces; that of the whole tumour cleansed from blood was two pounds.

Bingley, Yorkshire, February, 1800. 